\title{
BASIC PRINCIPLES OF BEHAVIORAL ECONOMICS AND PROSPECTS FOR THEIR APPLICATION IN THE PUBLIC HEALTH SYSTEM
}

DOI: 10.36740/WLek202009225

\author{
Lesia A. Rudenko' ${ }^{1}$, Vladyslav A. Smiianov ${ }^{2}$, Olha I. Smiianova ${ }^{2}$ \\ ${ }^{1}$ ALUNA PUBLISHING HOUSE, KONSTANCIN-JEZIORNA, POLAND \\ 2SUMY STATE UNIVERSITY, SUMY, UKRAINE
}

\begin{abstract}
Behavioral economics is a branch of economic theory that studies the influence of psychological factors on people's decisions in various life situations. At the same time, much attention is paid to situations where people behave differently than predicted by classical economic theory with its assumption of rationality and selfishness. Interesting possibility of application of behavioral economic in various spheres of human life and society, for example, reforms introducing, insurance system, public health and medicine (healthy living, disease prevention, following-up to the doctor's recommendations, improving the quality of care, etc.).
\end{abstract}

KEY WORDS: public health, behavioral economics, nudge, framing, bounded rationality effect

Wiad Lek. 2020;73(9 p. II):2026-2030

\section{INTRODUCTION}

The problem of determining the role of human in economy has always been relevant. For a long time there was a notion, first presented by Adam Smith, about «homo economicus» (economic man) - a rational egoist who knows exactly his interests and needs and always makes economically correct decisions according to them [1]. Such a person can be called "economical" person. However, over time, some inconsistencies began to emerge in practice and it turned out that human behavior is not always rational, and often quite opposite to rational. We will call such people «behavioral». This became a new subject of study for many economists in the 50-60s of the $20^{\text {th }}$ century. The new direction was called «behavioral economics» $[2,3]$.

Behavioral economics (BE) is the science that studies actual behavior of economic agents and corresponding psychological factors that influence economic behavior [2]. Behavioral economics is a branch of economic theory that studies the influence of psychological factors on people's decisions in various life situations [3]. At the same time, much attention is paid to situations where people behave differently than predicted by classical economic theory with its assumption of rationality and selfishness.

\section{THE AIM}

Introduction to the basic principles of behavioral economics and prospects for their application in the public health system.

\section{MATERIALS AND METHODS}

In the course of the research the bibliographic, bibliosemantic method, the method of system analysis and medical-statistical method. An analysis of foreign literature was conducted of behavioral economics. Also, an analysia of the study on the effectiveness of the reminding system for patients with hypertension, who were registered with family doctors, the study involved 2019 patients with hypertension.

\section{REVIEW AND DISCUSSION}

The founders of BE theory are considered to be an American economist Herbert Simon and a sociologist Daniel Kahneman, who received the Nobel Prize in Economics in 2002. In 2017, Richard Thaler was awarded the Nobel Prize for his contribution to the development of BE theory $[2,3]$. What's interesting is Thaler's important contribution is not only the development of behavioral economic theory, but also possibility of its application in various spheres of human life and society. For example, policy, reforms introducing, insurance system, public health and medicine (healthy living, disease prevention, following-up to the doctor's recommendations, improving the quality of care, etc.). People or institutions that are responsible for organizing the context in which people make decisions are called «architects of choice.» This can be a doctor who tells the patient about alternative treatments, or information institutions that influence people's behavior. Each health care specialist must be the «architect of choice» him- or herself.

R. Thaler unites his supporters under the banner of libertarian paternalism (LP). The libertarian component of 


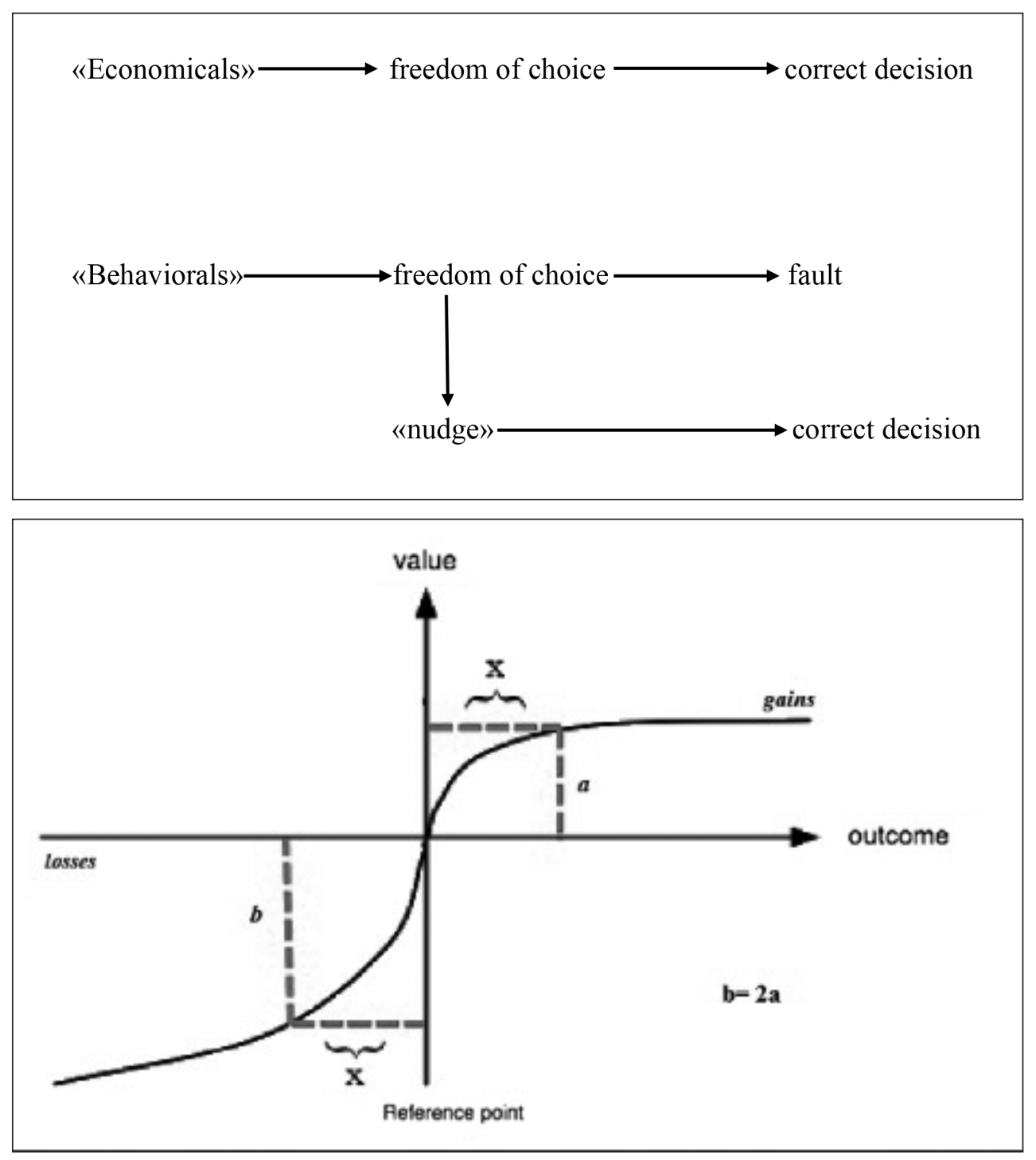

Fig. 1. Decision scheme.

Fig. 2. Loss aversion.

this strategy clearly states that, generaly, people should be free to do what they like and have freedom of choice. The paternalistic component determines the legitimate influence on people's behavior in such a way as directing their choices in areas that can improve their lives $[2,3]$. LP is a relatively weak, mild, and unobtrusive type of paternalism because choice is not blocked or overburdened. If people want to smoke cigarettes, eat sweets, not to worry about their health, LP will not force them to do the opposite, but rather will carefully try to guide people in areas that can improve their lives by "pushing" them.

Richard Thaler pays special attention to the motives that stimulate person to choose, which he called «nudge» (push) [4]. A push or a nudge is any aspect that changes people's behavior in a predictable way without forbidding any options [5]. Nudges are not orders. Placing fruits at eye level in the canteen is a nudge, and banning junk food is not.

"Behavioral" people in opposite to the "economical" make mistakes predictably (Fig. 1). Small and clearly insignificant details can be a nudge and create a huge impact on people's behavior. An interesting example of this principle is men's restrooms at Amsterdam Airport. The airport administration suggested drawing a fly in each urinal. It turned out reducing the cost of cleaning men's restrooms up to $80 \%[2,3]$.

As noted, classical economic theory considers perswon as rational, choosing only the best option for himself. But people aren't really like that at all. They are not homo economicus, but homo sapiens ("behaviorals"). Unfortunately, ordinary people often behave irrationally and incorrectly, even for their own health. They smoke, drink alcohol, eat poorly, suffer from overweight, keep unhealthy lifestyles, and do not follow a doctor's prescription, although most are well aware that it increases the risk of cardiovascular diseases, diabetes, cancer and can lead to premature death. Sociological research shows that most of behavioral people would like to get rid of bad habits and keep a healthy lifestyle. They need adequate nudges.

Psychologists and neurobiologists note the differences between two types of thinking: one is intuitive and automatic, and the other is reflective and rational. The automatic system is an intuitive reaction, and the reflective system is a conscious thought. The automatic system is fast, uncontrolled, unconscious, receives information from instincts, 
not related to comprehension. When a person dodges the ball, he uses an automatic system. The reflective system is slower, controlled, conscious, does not keep up with the automatic one. If people can rely on their automatic system without making a mistake, their lives will be much better and longer. Herbert Simon presented the term «limited rationality", when people often make decisions quickly based on automatic system to meet their needs, and that may not necessarily be the best option $[2,3,6]$. Behavioral economists encourage "choice architects" to participate in creating nudges for quick solutions (automatic system). Sunstein and Thaler's experiment of placing healthy food in school canteens at eye level and in the front row so that children make the right choice automatically is well known.

Consider some typical examples of human behavior.

Gains and losses. People do not like to lose. They suffer more from losing something than they will enjoy gaining it. Many experiments have shown that this ratio equals a difference in 2.25 - 2.5 times. This conclusion is called "loss aversion" (LA) [2, 3, 6] (Fig. 2). LA encourages inertia, i.e. a strong desire to maintain the state of affairs that exists today. LA plays the role of a kind of cognitive impulse that forces us to change nothing, even if the changes are in our favor.

For many reasons, people show a general tendency to follow the state of affairs that exists today. This phenomenon, which William Samuelson and Richard Zeckhauser (1988) called the «status-quo bias» occurs quite often [2]. For example, when you buy a new mobile phone, you have to set up a number of options. For each of these options, the manufacturer has set one default option. Research shows that no matter what kind default options are like, most people don't change them. Two important conclusions can be drawn from these studies. The first is never underestimate the force of inertia. Second, this force can be used. There is another example of using the default option. In the Netherlands, only $27.5 \%$ of the population agreed to be organ donors. In neighboring Belgium, organs are allowed to be taken from all people except those who have refused to donate (presumption of consent). As a result, 98\% of Belgians are donors. The effect of a well-chosen default option is just one example of a gentle nudge action.

Unwarranted optimism and overconfidence. Behavioral people usually think that they are much less likely than others to lose their jobs, have a heart attack, or get cancer. Drug addicts and gays underestimate the risk of contracting AIDS. Smokers are aware of the statistical risks, but generally believe that lung cancer and cardiovascular diseases are more commonly diagnosed in non-smokers. The wild popularity of lotteries is due to unwarranted optimism. Unwarranted optimism is a common feature of human life [2,3]. If people take risks because of unwarranted optimism, they can be helped by nudge. To do this, one can simply remind them of the real risks and tragic results and their optimism will fade a bit.

Framing is the dependence of decision-making on the submission of information. A person's choice often depends on how the problem is formulated. For example, if doctor says that out of a hundred operated cancer patients, ten die within five years, the patient is more likely to refuse surgery. And if the doctor says that under the same conditions, out of a hundred patients, ninety will live for five years, the decision on surgery may be different [7]. This means that frames are powerful nudges and it is needed to be very careful with them, especially in medical practice. Examples of framing: negative information carries negative associations, and positive - vice versa (the effect of our television - a constant negative, stress, depression, irritation). Example: refusal of vaccination [8].

Mechanism of social forces. Social forces are one of the most effective ways of nudge (fortunately or not). For example, in our city more and more dog owners take them for a walk, not forgetting to pick up cellophane bags. They do so by the example of others, despite the fact that there are no fines for walk without further cleaning. There are two types of social forces: information and social pressure/ impact. Most people worry what others will think about them, so they are able to follow the crowd to win their favor or avoid their condemnation [9]. For example: students' academic performance is significantly influenced by their environment (classmates or roommates). Obesity, smoking, alcohol consumption - all bad examples are catching. If your best friends are abusing this, then you are more likely to start abusing it. Visual feedback enhances the impact of social forces. People tend to do what others do, especially when they know the information will be public. The mechanism of social influence is very often used in economics, finance, politics. In our opinion, its use in medicine, disease prevention, formation of a healthy way of life is perspective.

Marketers, aware of the power of social forces, often emphasize that most people choose their product and switch from another brand (which became out-of date) to that they present $[8,10]$. They nudge people, talking about the modern preferences of the majority. If such information is also provided in digital support, the effect of such nudge is enhanced. Given the possibility of changing behavior by emphasizing statistical reality, an anti-smoking experiment was conducted at Montana college. The media claimed that «most of students (70\%) do not smoke.» It was proved that such a strategy significantly increased the effectiveness of social perception and achieved a statistically significant reduction in smoking.

Feedback. The best way to help people improve their performance is to provide them with feedback. A well-organized feedback system encourages a person to become an active participant, which in turn increases the efficiency of the process [10]. This approach can be especially relevant and promising in public health and medicine (maintaining a healthy lifestyle, disease prevention, following a doctor's appointment, etc.).

Priming. It is often possible to correct certain behaviors of people by invisibly getting certain information into the brain. Sometimes the slightest hint of an idea can evoke a certain association, which in turn can stimulate action. Such primes (stimuli) occur in social situations and can be 
powerful nudges $[2,3,5]$. For example, when sociologists ask respondents what they are going to do, they are more likely to act on their answers. This effect (simple measurement effect) can be enhanced by asking when and how they plan to do it. When Yale University students were invited to get vaccinated after a lecture on the risks of tetanus, only $3 \%$ did it. Another group of students was asked to choose a convenient day and time of vaccination, $28 \%$ of students did it, which is nine times more.

Forgetfulness. Nobody likes to forget something important. However, in just one day, the human brain has to process so much information that some of it is not stored. In our lives, managing this brain function can greatly facilitate the work of physicians. After all, according to statistics, the main problem of untimely (irregular) medication is forgetfulness. Physiologically, the brain normally perceives and processes reminders using an automatic system without additional effort.

The Department of Public Health of Sumy State University conducted a study on the effectiveness of the system of reminding patients with hypertension $(\mathrm{AH})$, who were registered with family doctors in Sumy. The analysis of the research results showed its high efficiency and prospects [11].

The study involved 2019 patients (men - 29.2\%, women $-70.8 \%$ ). At the first stage, a survey of patients with hypertension was conducted. The results of monitoring patients with hypertension showed that:

- $97.2 \%$ of patients are aware, according to their words, about prevention, the course of the disease and consequences of hypertension;

- $98.4 \%$ of respondents have their own pressure gauge to measure pressure;

- $37.1 \%$ irregularly monitor their pressure;

- $8.3 \%$ of patients did not measure pressure at all during current year;

- $52.3 \%$ of respondents take medicines irregularly, $20 \%$ do not take medication at all;

- $32 \%$ of respondents did not visit a doctor for prophylactic purposes;

- the main reason for irregular medication and blood pressure control patients indicate as forgetfulness (48.3\% among all patients);

- Almost all respondents noted that they were prescribed free prescriptions for antihypertensive drugs, but $37.4 \%$ of them did not use them for their intended purpose. The reason «I forget» occured in $66.7 \%$.

Basing on the results of the audit, a proposal for information and technological reminders to patients with SMS-messages about need to control blood pressure and medication was developed and implemented [11].

A year later, a re-audit showed the effectiveness of the implemented proposal:

- the number of patients with target pressure increased from $14 \%$ to $39 \%$;

- the number of hypertensive crises decreased by $17.8 \%$; - the number of patients who began to monitor blood pressure regularly and take medication increased by $31 \%$ [11].
Prospective risk assessment. This is a biased risks' assessment, when people can easily imagine them from a nuclear power plant accident, tsunami, earthquake, plane crash, and so on [12]. They mistakenly think these risks are high for them. And for the risks of stroke, heart attack, asthma attack people give low estimates, even if they occur much more often (the difference is up to twenty times the value). In all mentioned examples, the automatic system reacts sharply to risk without resorting to any tables with boring statistics. A good way to bring people back to reality is to constantly remind them of the real state of affairs.

\section{CONCLUSIONS}

1. People are prone to the perception of impulses (they are «nudge-receptive»). Even the most important decisions in life can be influenced by the ways and methods of behavioral economics.

2. During all life, a person is rarely affected by only one of the mechanisms of $\mathrm{BE}$, but mainly by combination and interaction of several factors that are in synergy with each other. It is still up to researchers to study these interactions and connections.

3. Today, we see that existing methods of health education have ceased to be effective (morbidity and mortality from chronic diseases are increasing, the number of vaccinated is decreasing, etc.). In our opinion, it is necessary to change the paradigm in this important part of public health and look closely at developments in the field of $\mathrm{BE}$. The proposed theory of «nudge» can open a new page in prevention of many diseases and promotion of a healthy lifestyle.

\section{REFERENCES}

1. Zdvizova M.V. Povedinkova ekonomichna teoriya v strukturi suchasnoho ekonomiko-teoretychnoho znannya [Behavioral economics theory in modern structure of economical-theoretic knowledge]. Taras Shevchenko National University of Kyiv. 2017: 449. (UA)

2. Thaler, Richard H. "Behavioral Economics: Past, Present, and Future". American Economic Review. 2016; 106 (7): 1577-1600. doi:10.1257/ aer.106.7.1577.

3. Thaler, Richard H. Mullainathan, Sendhil. "Behavioral Economics". In David R. Henderson (ed.). Concise Encyclopedia of Economics (2nd ed.). Indianapolis: Library of Economics and Liberty. 2008, ISBN 978-0-86597665-8. OCLC 237794267.

4. Sunstein Cass R. Why Nudge?: The Politics of Libertarian Paternalism. Yale University Press. 2014, ISBN 9780300212693.

5. Thaler R., Sunstein C. Nudge. Penguin Books. 2008.

6. Kahneman David. Thinking Fast and Slow. New York, NY: Farrar, Straus, and Giroux. 2013, pp. 10, 48, 119, 242-244, 271, 282-286, 289-299, 415-417. ISBN 978-0-374-53355-7.

7. Druckman J.N. "The Implications of Framing Effects for Citizen Competence". Political Behavior. 2001, 23 (3): 225-56. doi:10.1023/ A:1015006907312

8. Bryant J., Thompson S., Finklea, B. W. "Fundamentals of media effects". Waveland Press, Inc. 2013.

9. Seidman S. Contested knowledge: Social theory today. John Wiley \& Sons. 2016. 
10. Weingarten E., Chen Q., McAdams M., et al. "From primed concepts to action: A meta-analysis of the behavioral effects of incidentally presented words". Psychological Bulletin. 2016; 142 (5): 472-97. doi:10.1037/bul0000030

11. Smeyanov V.A., Smeyanova 0.I., TarasenkoS.V., Demikhova N.V. Otsenka effektivnosti vnedreniya mekhanizma vnutrennego audita kachestva meditsinskoy pomoshchi bol'nym arterial'noy gipertenziyey [Evaluating the effectiveness of the implementation of the mechanism of internal audit quality medical care to hypertensive patients]. Azorrbaycan Tibb Jurnali. 2014; 3: 62-67. (Ru)

12. Rausand M. "Chapter 1: Introduction". Risk Assessment: Theory, Methods, and Applications. John Wiley \& Sons. 2013, pp. 1-28. ISBN 9780470637647

\section{ORCID and contributionship:}

Lesia A. Rudenko: 0000-0003-0556-8263

\section{$D, E, F$}

Vladyslav A. Smiianov: 0000-0002-4240-5968 A, B, D, F

Olha I. Smiianova: 0000-0001-5823-924X B,E,F

\section{Conflict of interest:}

The Authors declare no conflict of interest.

\section{CORRESPONDING AUTHOR}

Vladyslav A. Smiianov

Sumy State University

Praci Str., 3, 40000, Sumy, Ukraine

tel: +380507713008

e-mail: vladlor60@ukr.net

Received: 14.04 .2020

Accepted: 03.08 .2020

A - Work concept and design, B - Data collection and analysis, C - Responsibility for statistical analysis,

D-Writing the article, $\mathbf{E}$-Critical review, $\mathbf{F}$ - Final approval of the article 